\title{
Pursuit of sexual function post-radical prostatectomy
}

\author{
Lisa G. Smyth, MD; Ivor M. Cullen, MD; David M. Quinlan, FRCS Urol
}

Department of Urology, St. Vincent's University Hospital, Dublin, Ireland

Cite as: Can Urol Assoc J 2013;7:E183-9. http://dx.doi.org/10.5489/cuaj.10192. Epub 2012 Jan 24.

\section{Abstract}

Introduction: In the event of the implementation of prostate cancer screening, younger men will be diagnosed more frequently. Erectile dysfunction (ED) is a frequent long-term complication in men post-radical prostatectomy (RP). Since the introduction of RP, urologists have strived to improve postoperative sexual function. There is little literature, however, in the area of ED prescribing and sexual pursuit in men post-RP. We assessed the pursuit of sexual function in this group of patients.

Methods: The study involved a detailed questionnaire sent to patients who have undergone radical retropublic prostatectomy (RRP) by one surgeon in one institution to ascertain the impact of ED on lifestyle and ED therapy prescription use.

Results: There was a response rate of $59 \%$; most patients who responded were in the 61 to 70 year age group at the time of the survey. About $25 \%$ of patients had intercourse more than once in the 4 weeks prior to the survey. A total $50 \%$ of patients had no problem or a very small problem with their sexual function. Overall $80 \%$ of patients were prescribed ED therapy, but less than $35 \%$ of them used it.

Conclusion: Sexual frequency peaked in younger patients who were 3 years or more from surgery. Of note, $46 \%$ of men either declined the offer of ED therapy or got the prescription and never used it. Only $34 \%$ of men had used their ED prescription in the last 4 weeks. Urologists frequently find that patients behave differently postoperatively, with less interest in sexual activity. Interestingly, we found that $50 \%$ of our patients classified their sexual function, as at most a small problem.

\section{Introduction}

Prostate cancer is the most common non-cutaneous malignancy affecting men. Its incidence is set to increase by $275 \%$ in Ireland over the next 10 years. ${ }^{1}$ There has been an increase in the number of young men diagnosed with clinically localized disease. As quality of life is more important and rates of distress from erectile dysfunction (ED) are higher in this age group, there is much controversy about ED postradical prostatectomy (RP).

$\mathrm{RP}$ is the gold standard for organ-confined disease. Unfortunately, there are significant long-term complications as a result of $\mathrm{RP}$, such as urinary incontinence and ED. Landmark work by Walsh and colleagues in the 1980s led to the development of the nerve-sparing RRP. ${ }^{2}$ These authors reported potency rates of $86 \%$ after bilateral nervesparing prostatectomy. ${ }^{3}$ The rates of ED post-RP vary greatly in the literature, from $40 \%$ to $75 \%$. ${ }^{4}$ The introduction of new technologies (laparoscopic and robotic) has led to improved incontinence rates, however ED remains a significant longterm side effect of treatment. Potency rates at 12 months vary for laparoscopic RP from $48 \%$ to $72 \%, 5,6$ and from $58 \%$ to $80 \%$ for robotic. ${ }^{7,8}$

We reviewed men who have undergone RRP in our department to assess their level of erectile function and pursuit of sexual function. Although there is plenty of literature on ED post-RRP, there is little investigation into the pursuit of improved sexual function, rate of prescribed ED therapy and its use.

\section{Methods}

We identified patients who underwent RRP in one centre by one surgeon. We searched PubMed for a validated healthcare questionnaire. We chose the UCLA prostate cancer index $(\mathrm{PCl})$, but modified it to include information on prescription use (Table 1 ). This is the most widely used prostate cancer specific health-related quality of life assessment tool. ${ }^{9}$ We sent out 349 questionnaires; 206 were returned. This gave us a response rate of $59 \%$, which compares well to other published patient sexual function post-RRP questionnaires. ${ }^{10}$ Of the 206 returned questionnaires, 196 were 
Smyth et al.

\begin{tabular}{|c|c|c|c|c|}
\hline \multicolumn{5}{|c|}{$\begin{array}{l}\text { This next section is about your SEXUAL FUNCTION AND SEXUAL SATISFACTION. } \\
\text { Many of the questions are very personal, but they will help us understand the important issues that you face every day. } \\
\text { Remember that your answers to this questionnaire will be kept confidential. } \\
\text { Please answer them honestly about THE LAST } 4 \text { WEEKS ONLY. }\end{array}$} \\
\hline \multicolumn{5}{|c|}{ How would you rate each of the following during the LAST 4 WEEKS? } \\
\hline (Circle one number on each line) & Poor & Fair & Good & Very good \\
\hline Your level of sexual desire? & 1 & 2 & 3 & 4 \\
\hline Your ability to have an erection? & 1 & 2 & 3 & 4 \\
\hline Your ability to reach orgasm (climax)? & 1 & 2 & 3 & 4 \\
\hline \multicolumn{5}{|c|}{ How would you describe the usual QUALITY of your erections? } \\
\hline None at all & & & 1 & (Circle one number) \\
\hline Not firm enough for any sexual activity & & & 2 & \\
\hline Firm enough for masturbation and foreplay only & & & 3 & \\
\hline Firm enough for intercourse & & & 4 & \\
\hline \multicolumn{5}{|c|}{ How would you describe the FREQUENCY of your erections? } \\
\hline I NEVER had an erection when I wanted one & & & 1 & \\
\hline I had an erection LESS THAN HALF the time I wanted one & & & 2 & \\
\hline I had an erection ABOUT HALF the time I wanted one & & & 3 & \\
\hline I had an erection MORE THAN HALF the time I wanted one & & & 4 & \\
\hline I had an erection WHENEVER I wanted one & & & 5 & \\
\hline
\end{tabular}

processed; we excluded 7 patients who had postoperative radiotherapy and 3 with artificial sphincters. There were 9 patients excluded from the results sections $1-3$ and 1 patient from section 4, as their questionnaires were incomplete.

\section{Results}

\section{Demographics}

The age range at the time of the survey was 44 to 77 years and 43 to 69 years at the time of surgery. The most common

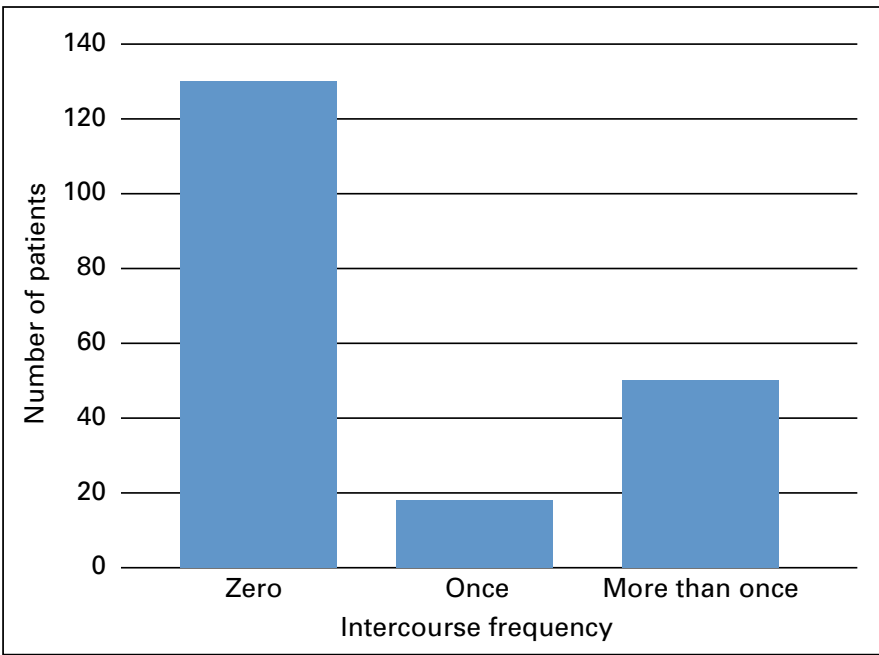

Fig. 1. Number of episodes of intercourse in the last 4 weeks. age group at the time of survey to respond was between 60 and 70 years. Most men were between 50 and 60 years when operated on. Most respondents had their surgery between 3 to 6 years before the survey (Table 2).

\section{Sexual frequency post-RRP}

We questioned patients on their sexual frequency in the last 4 weeks. Of the patients surveyed, 130 patients had not had intercourse, 17 had intercourse on one occasion and 49 on more than one occasion (Fig. 1). We then examined the relationship between age and years from surgery and sexual frequency (Fig. 2, Fig. 3). As expected, the men who were within the first 3 years of surgery had the lowest rates of intercourse. The men who were more than 3 years postsurgery had the most intercourse.

\section{Sexual problem post RRP}

We investigated whether our patients were distressed as a result of their sexual function (Fig. 4). We found that $50 \%$ felt that they had no problem/a small or very small problem with their sexual function. The other half described their sexual function as a moderate or big problem. We then analysed sexual problem in relation to age and time from surgery. The patients most affected were within 3 years of surgery, as opposed to those least affected who were 3 years or more post-RRP (Fig. 5). Surprisingly, men over 60 years were more distressed with their sexual function, and those between 50 and 60 years were least affected (Fig. 6). 


\begin{tabular}{lcc}
\hline \multicolumn{3}{c}{ Table 2. Age at surgery and survey, years from surgery } \\
\hline Age at survey & No. patients & $\%$ of patients \\
\hline $40-50$ & 4 & 2 \\
$50-60$ & 60 & 32 \\
$60-70$ & 96 & 51 \\
$>70$ & 27 & 14 \\
Total & 187 & 100 \\
\hline Age at surgery & & \\
\hline $40-50$ & 20 & 11 \\
$50-60$ & 94 & 50 \\
$60-70$ & 73 & 39 \\
Total & 187 & 100 \\
\hline Years from surgery & & \\
\hline$>1$ & 19 & 10 \\
$1-3$ & 33 & 18 \\
$3-6$ & 82 & 44 \\
$>6$ & 53 & 28 \\
Total & 187 & 100 \\
\hline
\end{tabular}

The prescription of ED therapy post-RRP

We collected the ED prescribing data on 195 patients, of which $81 \%$ were prescribed ED therapy. Out of the patients prescribed treatment, the therapy was used at least once in $67.7 \%$ of patients. However, 51 patients $(32.3 \%)$ never used their prescription (Table 3).

There were a total 64 patients using 5 different ED therapy agents in the last 4 weeks; vardenafil $(25 \%)$, alprostadil per urethra $(22 \%)$, sildenafil $(11 \%)$, tadalafil $(11 \%)$ and alprostadil injection (8\%). A total of $23 \%$ used their ED treatment agent more than once in the last 4 weeks, while there were 131 patients who did not use their prescription in the last 4 weeks. Of the 51 patients not using their prescription, 35 patients gave a reason $(68.6 \%)$. Ten patients said there was "no further desire" to continue treatment; this was the most common response. There were 4 patients who did not require it. With 4 patients, their partners were unwilling, 7 patients had medication concerns and 10 patients gave other reasons (wife deceased, laziness, poor mobility) (Fig. 7, part c).

\section{Discussion}

We developed our questionnaire from the UCLA PCI. We received a good response rate of $59 \%$, which underlines the importance of these issues to our patients. We feel the questionnaire was an appropriate method of evaluating ED, its treatment and its impact on our patients. We also assessed urinary function (data not included).

As expected, rates of sexual activity were lowest in patients who were within 3 years from surgery and increased to a peak at 3 to 6 years post-surgery. It is also highest in the

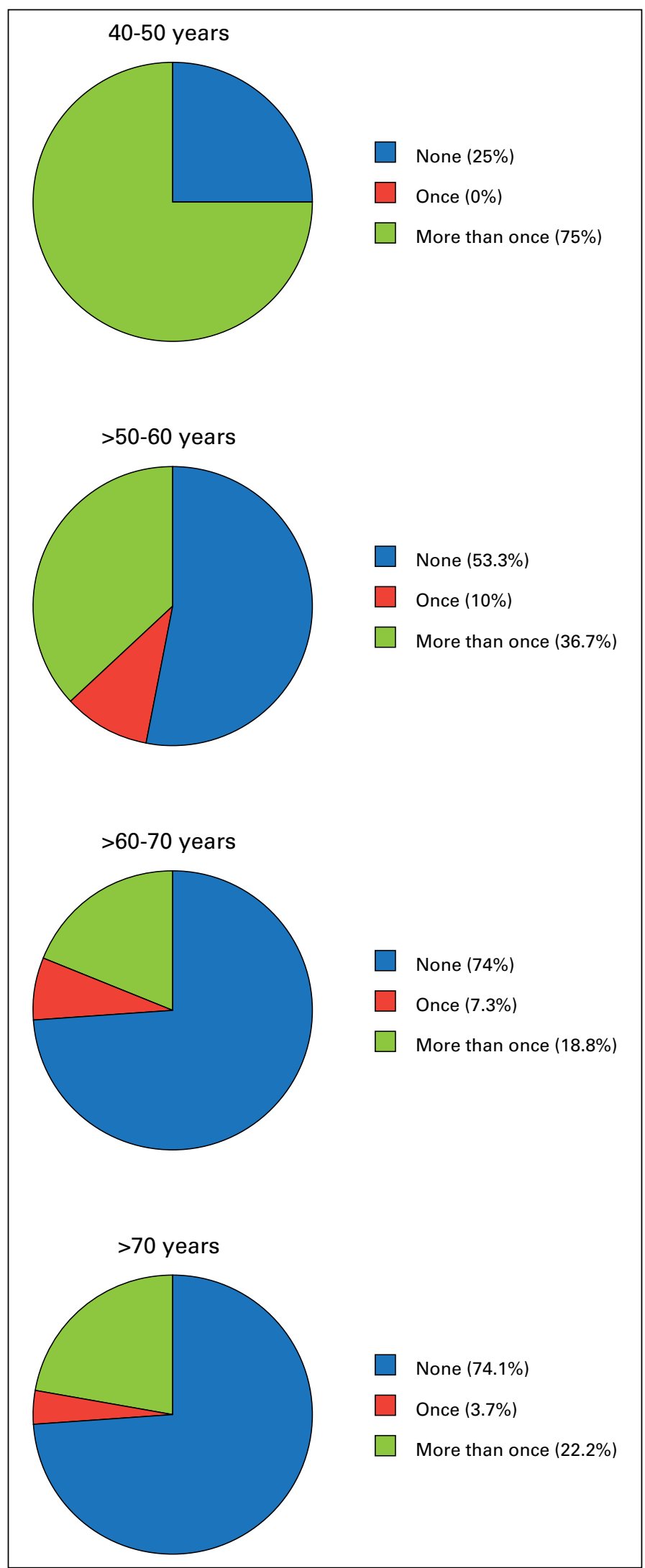

Fig. 2. Sexual frequency and age. 


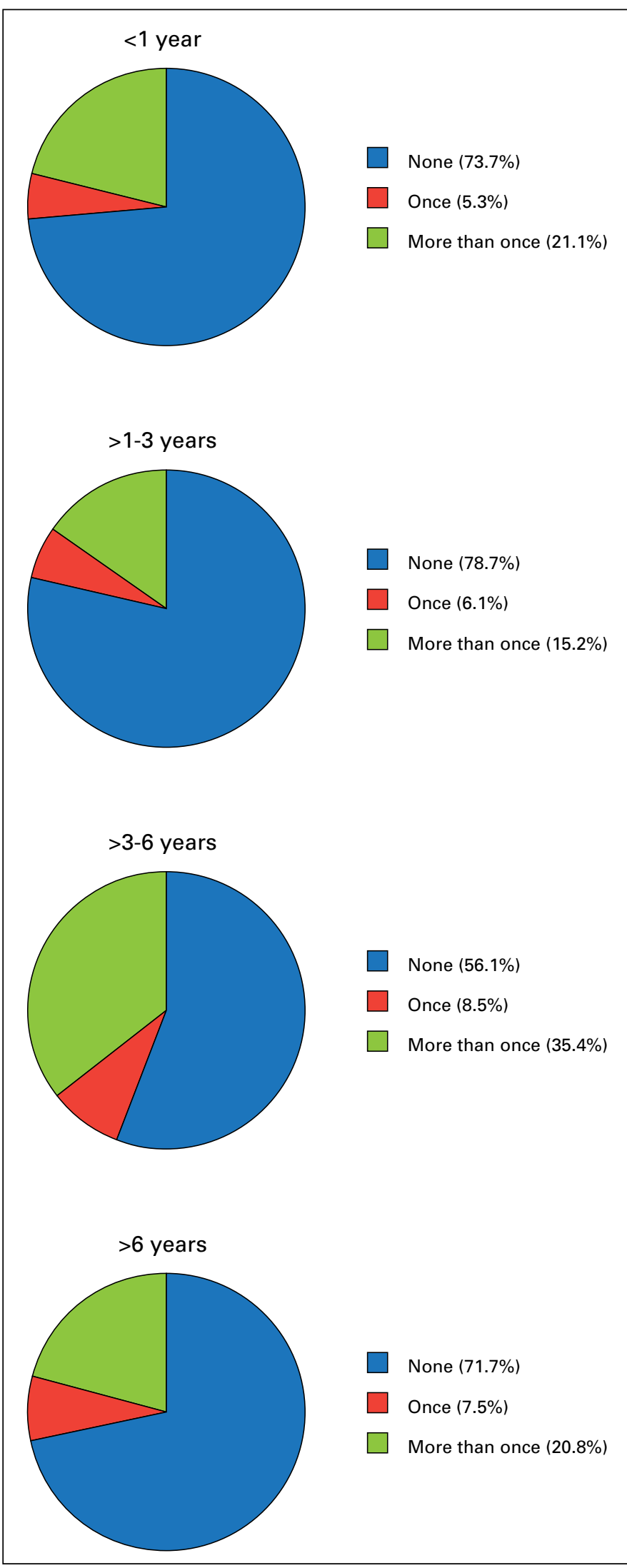

Fig. 3. Sexual frequency and years from surgery.
Table 3. Erectile dysfunction therapy prescribing and usage in the last 4 weeks

\begin{tabular}{lccc}
\hline Used & \multicolumn{3}{c}{ Prescribed } \\
\hline & Yes & No & Total \\
\cline { 2 - 4 } Yes & 107 & 0 & 107 \\
No & 51 & 37 & 88 \\
Total & 158 & 37 & 195 \\
\hline
\end{tabular}

younger age brackets and decreases with age.

The cause of ED associated with RRP is multifactorial. Factors include the surgeon's experience, surgical approach and neurovascular injury. Patient factors include preoperative erectile function, age, pre-existing conditions (smoking, hypertension and atherosclerosis) and the emotional consequences of the cancer and illness on the patient. Poor preoperative erectile function is the most important patient factor and it is imperative to remember that ED may be present in over $50 \%$ of patients preoperatively. ${ }^{11}$

Cavernous smooth muscle depends on neurovascular and psychological factors. Preservation of the erectile function after radical prostatectomy depends on precise and adequate separation of the cavernous nerves in the neurovascular bundle from the prostate. ${ }^{12}$ Even with bilateral nerve-sparing surgery, neuropraxia can lead to delayed recovery of erectile function. The recovery of the natural erection can take up to 24 months.

Our questionnaire examined the impact of sexual function on patients' quality of life. In general, the importance of sexual function decreases with increasing age ${ }^{13}$ and many patients will adjust to their changed sexual function, especially if their cancer is cured. Urologists have gone to great lengths to achieve improvements in sexual function post-RRP. ${ }^{14-16}$ However, in our study $50 \%$ had either no, a very small or a small problem with their sexual function postoperatively, while there were $50 \%$ who had moderate or big issues with their sexual function. These data reflect other papers on quality of life post-RRP. ${ }^{17}$

Treatment of ED is essential to alleviate symptoms of inadequacy, anxiety and depression. In our study, 158 patients had therapy prescribed. Of these, $32 \%$ never used

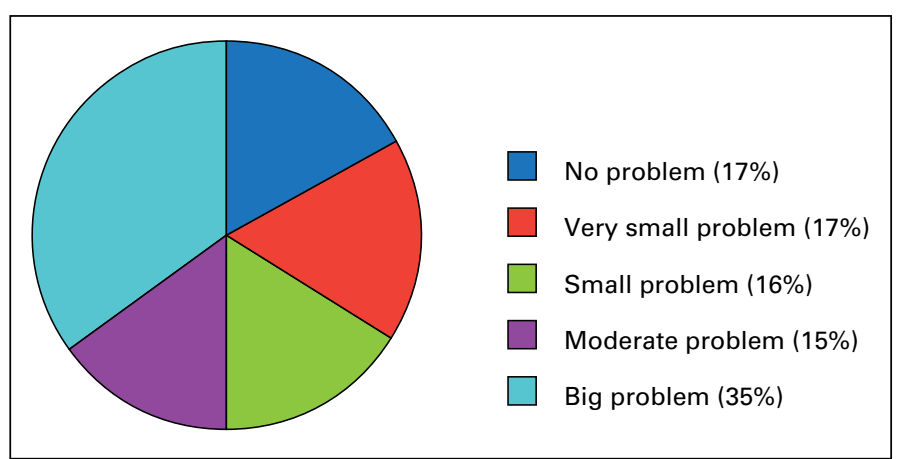

Fig. 4. How big a problem has sexual function been over the last 4 weeks? 


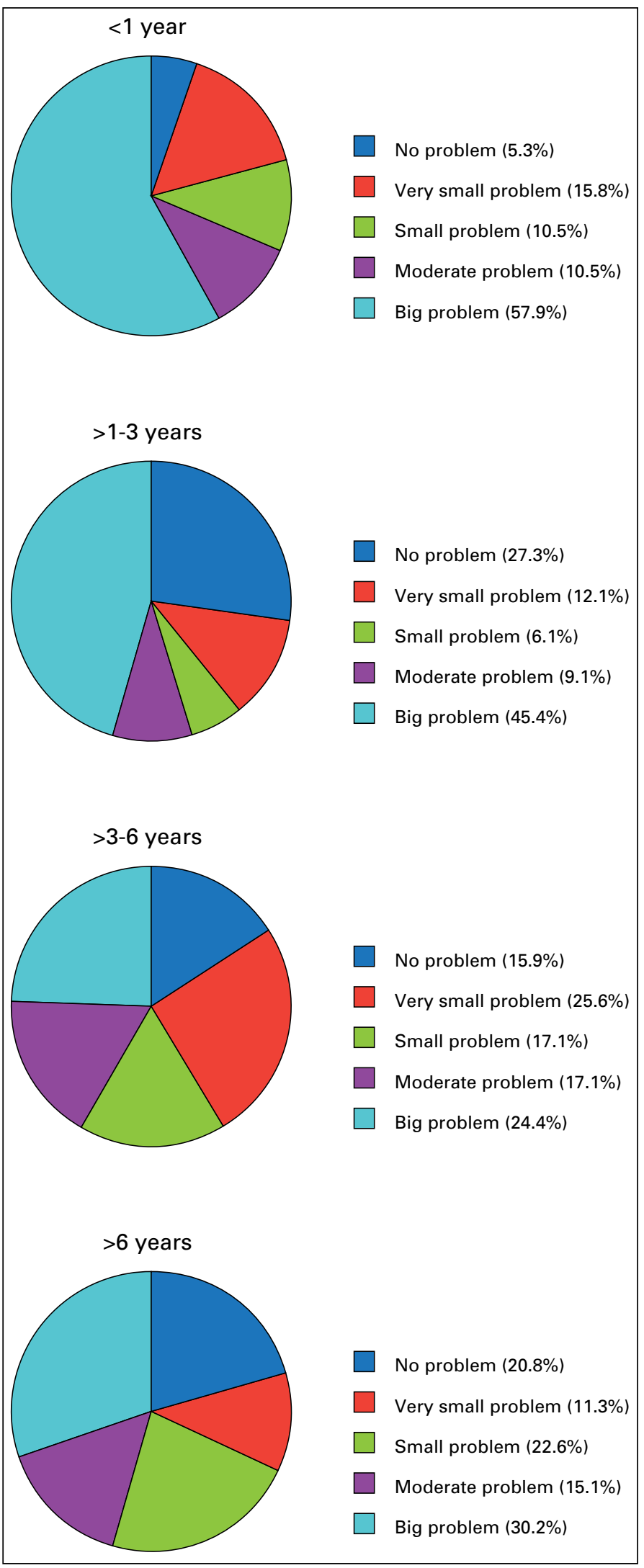

Fig. 5. Sexual problem and years from surgery.

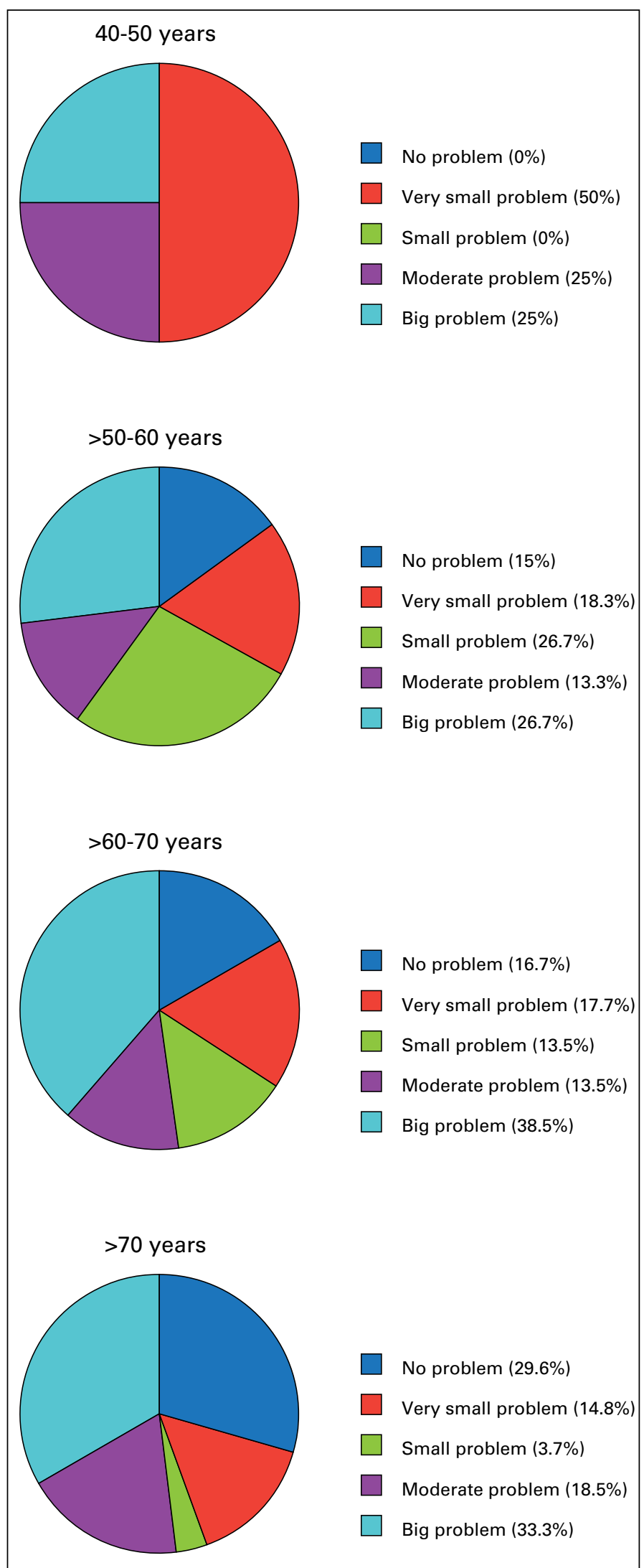

Fig. 6. Sexual problem and age. 


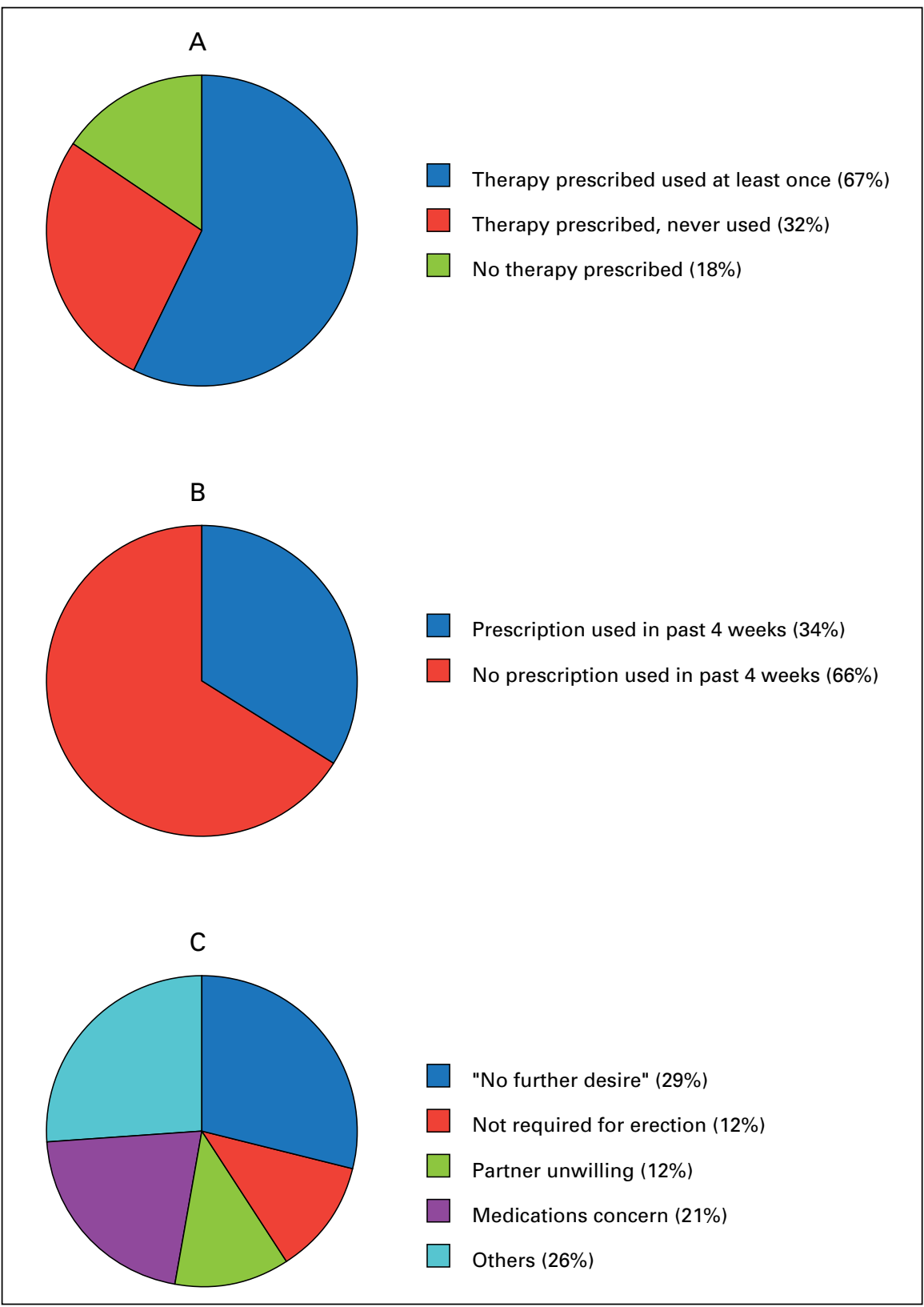

Fig. 7. (A) Rates of erectile dysfunction (ED) therapy prescribed; (B) ED therapy used in the last 4 weeks; and $(C)$ reasons for not using ED therapy.

the prescription. The most frequent reason for this was lack of desire (29\%). It is important to note that over $20 \%$ avoided ED therapy due to medication concerns. This underlines the importance of proper patient counselling.

The options available to men post-RP include pharmacological, assistive aids and implants. Stepwise trial of treatments from oral to injections to aids or implants should be followed. From our patient group, 64 patients had used an ED therapy in the last 4 weeks. The most commonly used medication was vardenafil (25\%). The phosphodiesterase type 5 (PD5) inhibitors are the most commonly prescribed

\section{References}

first-line therapy for ED post-RP. A good response to PD5 inhibitors depends on the dose prescribed, age of the patient, neurovascular injury and delay to treatment. Sildenafil has previously been found to be ineffective in the first 9 months, ${ }^{18}$ but its efficacy increases with time as the nerves recover from intra-operative injury.

Despite their effectiveness, assistive aids are discarded by $30 \%$ to $50 \%$ of men after 1 year. ${ }^{4}$ In a similar study, Salonia and colleagues revealed that $50 \%$ of patients post-bilateral nerve-sparing surgery freely decided not to start therapy; of those who commenced therapy, $73 \%$ eventually discontinued it. ${ }^{19}$ The high dropout rates for ED treatment demonstrate that it is vital for urologists to educate patients on treatment options, their correct use and warning of possible side effects.

\section{Conclusion}

Sexual frequency peaks for younger men and for those who are 3 to 6 years postsurgery; $45 \%$ of men will either decline a prescription or receive and never use it. It is essential that urologists and general practitioners inform patients of ED post-RP. Additionally, patients need to be counselled on treatments and their potential side effects. Interestingly, we found that half of our patients had no or only a small concern about their sexual function. It should be pointed out that despite urologists' efforts to restore sexual function, about $50 \%$ of men are not interested in perusing sexual function after RP; this is likely a result of a change in their priorities after their cancer diagnosis and treatment.

Competing interests: None declared.

This paper has been peer-reviewed.

1. National Cancer Registry. Trends in lrish cancer incidence 1994-2002, with projections to 2020. 2006. httr://www.ncri.ie/pubs/pubfiles/proi_2020.pdf. Accessed December 20, 2011. 
2. Quinlan D, Epstein Il, Carter BS, et al. Sexual function post radical prostatectomy: influence of preservation of the neurovascular bundles. J Urol 1991;145:998-1002.

3. Walsh P. Patient reported urinary continence and sexual function after anatomic radical prostatectomy. J Urol 2000;164:242

4. Matthew A, Goldman AT, Rachtenberg J, et al. Sexual dysfunction post prostatectomy: Prevalence, treatments, restricted use of treatments and distress. J Urol 2005;174:2105-10. http://dx.doi. org/10.1097/01.ju.0000181206.16447.e2

5. Su L, Link RE, Bhayani SB, et al. Nerve sparing laparoscopic radical prostatectomy: Replicating the open surgical technique. Urology 2004;64:123-7. http://dx.doi.org/10.1016/j.urology.2004.02.010

6. Wagner A, Link R, Pavlovich C, et al. Use of a validated quality of life questionnaire to assess sexual function following laparoscopic radical prostatectomy. Int J Impot Res 2006;18(1):69-76. http://dx.doi. org/10.1038/s.i.jir.3901376

7. Menon M, Shrivastava A, Kaul S, et al. Vattiki Institute prostatectomy: contemporary technique and analysis of results. Eur Urol 2004;51:648-58. http://dx.doi.org/10.1016/i.eururo.2006.10.055

8. Zorn K, Gofirt ON, Orvieto MA, et al. Robotic-assisted prostatectomies plateau? The Columbia University expereince. Eur Urol 2007;51:755-63. http://dx.doi.org/10.1016/i.eururo.2006.10.019

9. Karakiewicz P, Kattan MW, Tanguay $S$, et al. Cross-cultural validation of the UCLA prostate cancer index. Urology 2003;61:302-7. http://dx.doi.org/10.1016/S0090-4295(02)02245-8

10. Jenkins R, Schover LR, Fouladi RT, et al. Sexuality and health related quality of life after prostate cance in African-American and white men treated for localised disease. J Sex Marital Ther 2004;30:79-93. http://dx.doi.org/10.1080/00926230490258884
11. Mulcahy J. Erectile function after radical prostatectomy. Semin Urol Oncol 2000;18:71-5.

12. Walsh P, Donker P. Impotence following radical prostatectomy: insight into etiology and prevention. J Urol 1982;3:492-7.

13. Kirschner-Hermannd R, Jakse G. Quality of life following radical prostatectomy. Crit Rev Oncol Hematol 2002;43:141-51.

14. Quinlan D, Nelson RJ, Walsh PC. Cavernous nerve grafts restore erectile dysfunction in denervated rats. J Urol 1991;145:380-3.

15. Burgers J, Nelson RJ, Quinlan DM, et al. Nerve growth factor, nerve grafts and amniotic membrane grafts restore erectile dysfunction in rats. J Urol 1991;146:463-8.

16. Kim E, Scardino PT, Kadmon D, et al. Interposition sural nerve grafting during radical retropubic prostatectomy. Urology 2001;57:211-6. http://dx.doi.org/10.1016/50090-4295(00)00831-1

17. Pedersen $K V$, Carlsson $P$, Rahmquist $M$, et al. Quality of life after radical retropubic prostatectomy for carcinoma of the prostate. Eur Urol 1993;24:7-11.

18. Zagaja $G$, Mhoon DA, Aikens JE, et al. Sidenafil in the treatment of erectile dysfunction after radical prostatectomy. Urology 2000;56:631-4. http://dx.doi.org/10.1016/50090-4295(00)00659-2

19. Salonia $A$, Gallina $A$, Zanni $G$, et al. Acceptance of and discontinuation rate from erectlie dysfunction oral treatment in patients following bilateral nerve sparing radical prostatectomy. Eur Urol 2008;53:564-70. http://dx.doi.org/10.1016/i.eururo.2007.08.016

Correspondence: Dr. Lisa G. Smyth, Department of Urology, Mid Western Regional Hospital, Dooradoyle, Co Limerick, Ireland; elizabethsmyth@rcsi.ie 